\title{
JIMMBA
}

\section{Pengaruh Environmental Consciousness dan Green Perceived Value Terhadap Green Repurchase Intention dengan Green Satisfaction sebagai Variabel Intervening}

\author{
Anggun Ma'rifatun ${ }^{1}$, Sulis Riptiono ${ }^{2}$ \\ 1Sekolah Tinggi Ilmu Ekonomi Putra Bangsa \\ ${ }^{2}$ Sekolah Tinggi Ilmu Ekonomi Putra Bangsa \\ Email: anggunmarifatun565@gmail.com
}

\section{ARTICLE INFO}

Article History:

Received:March 2nd 2020

Accepted:April 30 th 2020

Published:August $31^{\text {st }} 2020$

Keywords:

Environmental

Consciousness, Green

perceived Value, Green

Satisfaction, Green

Repurchase Intention

\begin{abstract}
Penelitian ini bertujuan untuk mengetahui pengaruh environmental consciousness dan green perceived value terhadap green repurchase intention melalui green satisfaction sebagai variabel intervening. Populasi dalam penelitian ini adalah masyarakat di Kabupaten Kebumen yang pernah melakukan pembelian sayuran organik. Sampel penelitian sebanyak 100 orang dengan metode purposive sampling. Metode yang digunakan dakam penelitian ini adalah metode kuantitatif. Analisis data mengunakan analisis jalur dengan progam SPSS 23 dan sobel test. Hasil penelitian ini menunjukan bahwa environmental consciousness dan green perceived valueberpengaruh signifikan terhadap green satisfaction. Selanjutnya environmental consciousness tidak berpengaruh terhadap green repurchase intention, sedangkan green perceived value dan green satisfaction berpengaruh dan signifikan terhadap green repurchase intention. Serta green satisfaction dapat memediasi antara environmental consciousness dan green perceived value terhadap green repurchase intention.
\end{abstract}

\section{Pendahuluan}

Masalah lingkungan memang menjadi masalah yang sangat memprihatinkan di berbagai penjuru dunia. Semakin modern dan semakin berkembangnya zaman memberikan dampak positif dan negatif terhadap lingkungan kehidupan. Dampak negatif masalah lingkungan seperti pencemaran lingkungan, kerusakan hutan, dan pemanasan global yang kian memburuk dari tahun-ketahun. Begitupun dengan industri pangan yang dengan dalih kecukupan pangan menjadi semakin mengabaikan kebutuhan bumi untuk diperhatikan dan dilestarikan. Penggunaan pupuk kimia dan pestisida sangat bersifat merusak unsur hara tanah.Akhir-akhir ini kesadaran masyarakat terhadap lingkungan hidup mulai meningkat 
setelah melihat banyaknya kerusakan lingkungan yang terjadi.Konsumen menjadi sangat perhatian terhadap keterbatasan sumber daya yang ada di bumi, kesehatan dan kerusakan lingkungan, sehingga mulai melirik produk yang lebih bertanggung jawab kepada lingkungan. Sehingga pemasar yang pintar akan memandang masalah lingkungan hidup sebagai peluang untuk memuaskan kebutuhan dan keinginan konsumen, Pemasar akan mengaplikasikan masalah lingkungan dalam aktivitas pemasaran yang mereka lakukan, sehingga menimbulkan fenomena baru dalam dunia pemasaran berupa konsep Green Marketing.Green marketing merupakan seluruh aktivitas yang didesain untuk menghasilkan dan memfasilitasi semua perubahan yang diharapkan dapat memuaskan kebutuhan dan keinginan manusia, dengan dampak minimal pada kerusakan lingkungan alam (Lam, et al, 2016). Fenomena green marketing yang terjadi saat ini, mengakibatkan penjualan green product mengalami peningkatan yang menyebabkan konsumen bersedia melakukan pembelian atau mengkonsumsi green product.Berkaitan dengan permasalahan tersebut trend keamanan pangan (food safety) menjadi isu yang positif dalam produk pangan.Salah satu produk yang menggunakan teknik green product adalah produk sayur organik.Produk sayur organik ini diproses atau diproduksi tanpa menggunakan pupuk kimia atau pestisida sintetis, tetapi menggunakan pupuk organik seperti menur dari kotoran ternak dan fases ternak yang dikenal sebagai pupuk kandang serta kompos yang terbuat dari limbah hasil pertanian yang telah mengalami fermentasi spontan. Oleh karena itu peneliti melakukan observasi terhadap 30 responden di Kabupaten Kebumen menunjukan bahwa 80\% masyarakat di Kabupaten Kebumen sudah pernah mengkonsumsi green product atau sayuran organik. Berikut tabel hasil survei yang telah dilakukan peneliti terhadap 30 responden pada Green Repurchase Intention pada produk sayuran organik di Kabupaten Kebumen.

Tabel 1. Hasil Observasi Pembelian pada Konsumen Sayuran Organik

\begin{tabular}{clc}
\hline No & \multicolumn{1}{c}{ Pembelian } & Jumlah \\
\hline 1. & Niat membeli ulang & 22 \\
2. & Tidak berniat membeli ulang & 8 \\
\hline & Jumlah & 30
\end{tabular}

Tabel 1.dijelaskan dari total 30 responden, 22 orang mengatakan berniat membeli kembali terhadap produk organik dan 8 orang mengatakan tidak berniat membeli kembali. Dari 22 orang mengatakan berniat membeli kembali, terdapat alasan yang telah dirangkum dalam tabel berikut:

Tabel 2. Alasan Pembelian Ulang pada Konsumen Sayuran Organik

\begin{tabular}{llccc}
\hline No & Alasan pembelian ulang & Jumlah & Presentase & Variabel \\
\hline 1. & $\begin{array}{l}\text { Menjaga komitmen } \\
\text { perlindungan lingkungan } \\
\text { manfaat yang dirasakan } \\
\text { konsumen setelah }\end{array}$ & 6 & $27 \%$ & $\begin{array}{c}\text { Environmental } \\
\text { consciousness } \\
\text { mengkonsumsi sayuran } \\
\text { organik }\end{array}$ \\
$\begin{array}{l}\text { preen perceived } \\
\text { value }\end{array}$ \\
membeli sayuran organik
\end{tabular}


Tabel 2. Menjelaskan alasan konsumen melakukan pembelian ulang pada produk sayuran organik karena menjaga komitmen perlindungan lingkungan berjumlah 6 orang atau dengan persentase $27 \%$, alasan karena manfaat yang dirasakan konsumen setelah mengkonsumsi sayuran organik berjumlah 9 orang atau dengan persentase $41 \%$, alasan puas akan keputusan pembelian sayuran organik berjumlah 7 orang atau dengan persentase $32 \%$.

Environmental Consciousness menurut Ariffin Shahira, et al, 2016 adalah dimana individu menyadari masalah lingkungan dan menunjukan dukungan usaha dalam menumbuhkan dan membina kesadaran untuk melestarikan lingkungan berdasarkan tata nilai, yaitu tata nilai dari lingkungan itu sendiri dengan filsafat hidup secara damai dengan alam lingkungannya. Akan tetapi realita yang terjadi di Kabupaten Kebumen, sebagian masyarakat masih mengabaikan lingkungan.Namun dengan demikian bukan berarti tingkat kesadaran lingkungan di Kabupaten Kebumen itu rendah.Disini dibuktikan melalui observasi yang telah dilakukan peneliti bahwa konsumen yang pernah melakukan pembelian green product (sayuran organik) karena menjaga komitmen perlindungan lingkungan yang termasuk dalam indikator environmental consciousness. Dengan semakin tinggi environmental consciousness maka semakin tinggi niat beli ulang atau green repurchase intention (Ariffin Shahira, et al, 2016)

Menurut Chen and Chang, (2012) greenperceived value adalah penilaian konsumen secara keseluruhan dari manfaat yang diterima dan apa yang dikorbankan suatu produk atau jasa yang diberikan pada lingkungan konsumen, harapan berkelanjutan dan kebutuhan hijau (kebutuhan produk organik). Dengan semakin tinggi green perceived valueakan meningkatkan green satisfaction atau kepuasan dari konsumen, dan akan berimplikasi pada niat beli ulang atau green repurchase intention (Lam, et al, 2016)

Menurut Kurniawati, et al, (2018) green satisfaction sebagai level kesenangan atau kebahagiaan dari pemenuhan konsumsi yang memuaskan dengan pertimbangan lingkungan pelanggan, sesuai dengan harapan dan kebutuhan hijau. Semakin tinggi green satisfaction atau kepuasan dari konsumen maka semakin tinggi niat beli ulang atau green repurchase intention (Lam, et al, 2016).

\section{Kajian Teori dan Telaah Literatur}

\section{Green Repurchase Intention}

Green repurchase intention merupakan perilaku pembelian hijau dimana konsumen merespon positif terhadap kualitas produk ramah lingkungan dan berniat untuk melakukan kunjungan kembali atau mengkonsumsi kembali produk ramah lingkungan di perusahaan tersebut (Lam et al., 2016). Menurut Chinho dan Watcharee, 2014 indikator Green Repurchase Intention adalah sebagai berikut :(1) Penggunaan ulang produk (2) Pembelian produk (3) Rekomendasi produk (4) Antisipasi produk.

\section{Green Satisfaction}

Menurut Kurniawati, et al, (2018) green satisfaction sebagai level kesenangan atau kebahagiaan dari pemenuhan konsumsi yang memuaskan dengan pertimbangan lingkungan pelanggan, sesuai dengan harapan dan kebutuhan hijau. Menurut Kurniawati, et al, (2018) indikator dari 
Green Satisfaction adalah sebagai berikut: (1) Konsumen merasa senang (2) Puas atas keputusan membeli produk (3) Merasa ikut berkontribusi dalam lingkungan (4) Puas akan kepedulian lingkungan yang diberikan suatu produk (5) Puas terhadap kinerja lingkungan.

\section{Environmental Consciousness}

Environmental Consciousness menurut Ariffin Shahira, et al, (2016) adalah dimana individu menyadari masalah lingkungan dan menunjukan dukungan usaha dalam menumbuhkan dan membina kesadaran untuk melestarikan lingkungan berdasarkan tata nilai, yaitu tata nilai dari lingkungan itu sendiri dengan filsafat hidup secara damai dengan alam lingkungannya. Menurut Maniatis, (2015) indikator environmental consciousness adalah sebagai berikut : (1) Pengetahuan tentang solusi lingkungan (2) Pengetahuan tentang pelabelan produk organic (3) Pengetahuan tentang manfaat lingkungan (4) Pengetahuan tentang manfaat ekonomi (5) Komitmen perlindungan lingkungan.

\section{Green Perceived Value}

Menurut Chen and Chang., (2012) greenperceived value adalah penilaian konsumen secara keseluruhan dari manfaat yang diterima dan apa yang dikorbankan suatu produk atau jasa yang diberikan pada lingkungan konsumen, harapan berkelanjutan dan kebutuhan hijau (kebutuhan produk organik). Menurut Kurniawati, et al., (2018) indikator Green Perceived Value adalah sebagai berikut (1)Benefit for consumers(2) Environmental Consciousness(3)Environmental concern(4)Standar of quality(5)Price.

0

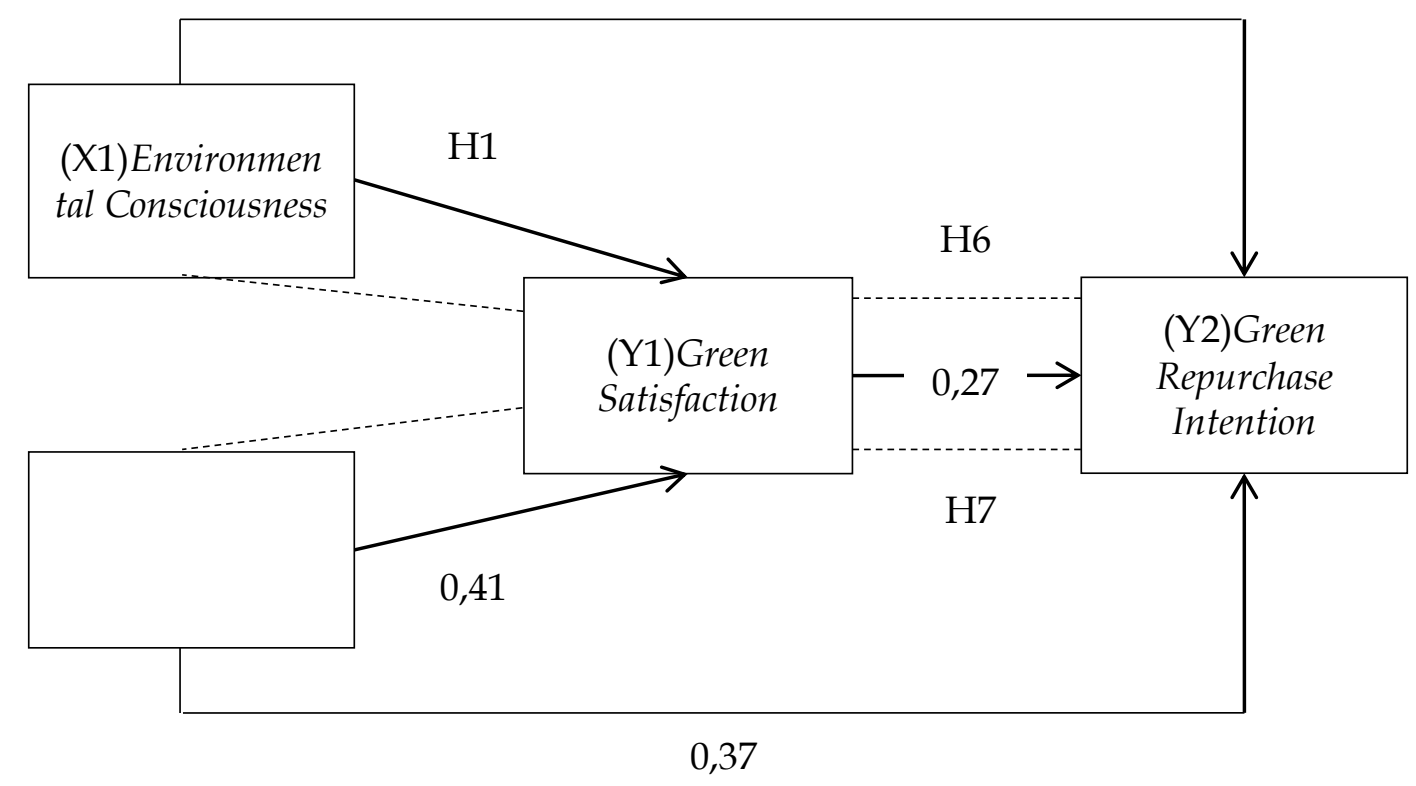

Gambar 1. Kerangka Teoritis 
Penelitian ini dilakukan pada konsumen yang pernah melakukan pembelian sayuran organik di Kabupaten Kebumen. Pengambilan sampel menggunakan metode nonprobalibility sampling dengan teknik purposive sampling, dengan jumlah responden sebanyak 100 orang. Pengumpulan data menggunakan kuesioner dengan skala likert, dengan masing-masing kuesioner mengenai environmental consciousness5 item pertanyaan, kuesioner green perceived value5 item pertanyaan, kuesioner green satisfaction 5 item pertanyaan dan green repurchase intention4 item pertanyaan.

Teknik pengumpulan data yang dilakukan dengan cara : (1) menyebar kuesioner; (2) wawancara; (3) studi pustaka. Instrumen dalam penelitian ini dilakukan dengan menggunakan kuesioner yang ditujukan untuk memperoleh jawaban responden. Alat bantu pengolahan data menggunakan SPSS for windows versi 23.0. teknik analisis data yang digunkan meliputi : (1) Uji Validitas dan Uji Reliabilitas (2) Uji Asumsi Klasik (3) Uji Hipotesis (4) Analisis Korelasi (5) Uji Sobel (6) Analisis Jalur.

\section{Hasil dan Pembahasan}

\section{Uji Validitas}

Tabel 3. Uji Validitas variabel Environmental Consciousness

\begin{tabular}{lcllll}
\hline Variabel & Butir & R hitung & R tabel & Signifikansi & Keterangan \\
\hline Environmental & 1 & 0,724 & 0,196 & 0,000 & Valid \\
consciousness & 2 & 0,816 & 0,196 & 0,000 & Valid \\
& 3 & 0,807 & 0,196 & 0,000 & Valid \\
& 4 & 0,794 & 0,196 & 0,000 & Valid \\
& 5 & 0,725 & 0,196 & 0,000 & Valid \\
\hline
\end{tabular}

Sumber: data primer diolah, tahun 2020

Tabel 4. Uji Validitas Variabel Green Perceived Value

\begin{tabular}{lcclll}
\hline Variabel & Butir & $\mathrm{R}$ hitung & $\mathrm{R}$ tabel & Signifikansi & keterangan \\
\hline Green Perceived & 1 & 0,747 & 0,196 & 0,000 & Valid \\
Value & 2 & 0,809 & 0,196 & 0,000 & Valid \\
& 3 & 0,778 & 0,196 & 0,000 & Valid \\
& 4 & 0,726 & 0,196 & 0,000 & Valid \\
& 5 & 0,665 & 0,196 & 0,000 & Valid
\end{tabular}

Sumber: data primer diolah, tahun 2020

Tabel 5. Uji Validitas Variabel Green Satisfaction

\begin{tabular}{lcclll}
\hline Variabel & Butir & R hitung & R tabel & Signifikansi & keterangan \\
\hline Green & 1 & 0,770 & 0,196 & 0,000 & Valid \\
Satisfaction & 2 & 0,860 & 0,196 & 0,000 & Valid \\
& 3 & 0,870 & 0,196 & 0,000 & Valid \\
\hline
\end{tabular}


Jurnal Ilmiah Mahasiswa Manajemen, Bisnis dan Akuntansi 2(4) Agustus 2020

\begin{tabular}{lllll}
\hline 4 & 0,875 & 0,196 & 0,000 & Valid \\
5 & 0,835 & 0,196 & 0,000 & Valid
\end{tabular}

Sumber: data primer diolah, tahun 2020

Tabel 6. Uji Validitas Green Repurchase Intention

\begin{tabular}{llllll}
\hline Variabel & Butir & R hitung & R tabel & Signifikansi & keterangan \\
\hline Green & 1 & 0,733 & 0,196 & 0,000 & Valid \\
Repurchase & 2 & 0,755 & 0,196 & 0,000 & Valid \\
Intention & 3 & 0,829 & 0,196 & 0,000 & Valid \\
& 4 & 0,797 & 0,196 & 0,000 & Valid \\
\hline
\end{tabular}

Sumber: data primer diolah, tahun 2020

Berdasarkan tabel diatas menunjukkan semua environmrntal consciousness, green perceived value, green satisfaction, dan green repurchase intentiondinyatakan valid karena $\mathrm{r}$ hitung > rtabel $(0,196)$, dengan tingkat signifikansi sebesar 0,000 <0,05 sehingga semua item yang dipakai dinyatakan valid atau sah.

\section{Uji reliabilitas}

Tabel 7. Hasil Uji Reliabilitas

\begin{tabular}{llll}
\hline Variabel & $\mathbf{r}_{\text {kritis }}$ & $\begin{array}{l}\text { Cronbach's } \\
\text { Alpha }\end{array}$ & Keterangan \\
\hline Environmental Consciousness & 0,60 & 0,832 & Reliabel \\
Green Perceived value & 0,60 & 0,798 & Reliabel \\
Green Satisfaction & 0,60 & 0,891 & Reliabel \\
Geen Repurchase Intention & 0,60 & 0,783 & Reliabel
\end{tabular}

Sumber: Data primer diolah, Tahun 2020

Berdasarkan Tabeltersebut hasil analisis dapat dijelaskan bahwa instrumen-instrumen yang digunakan dalam penelitian ini memiliki nilai Cronbach's Alpha $>\mathrm{r}_{\text {kritis }}(0,60)$. Berdasarkan hasil tersebut, dapat disimpulkan bahwa semua instrumen dalam penelitian dinyatakan reliable.

\section{Uji Asumsi Klasik}




\section{Uji Normalitas}

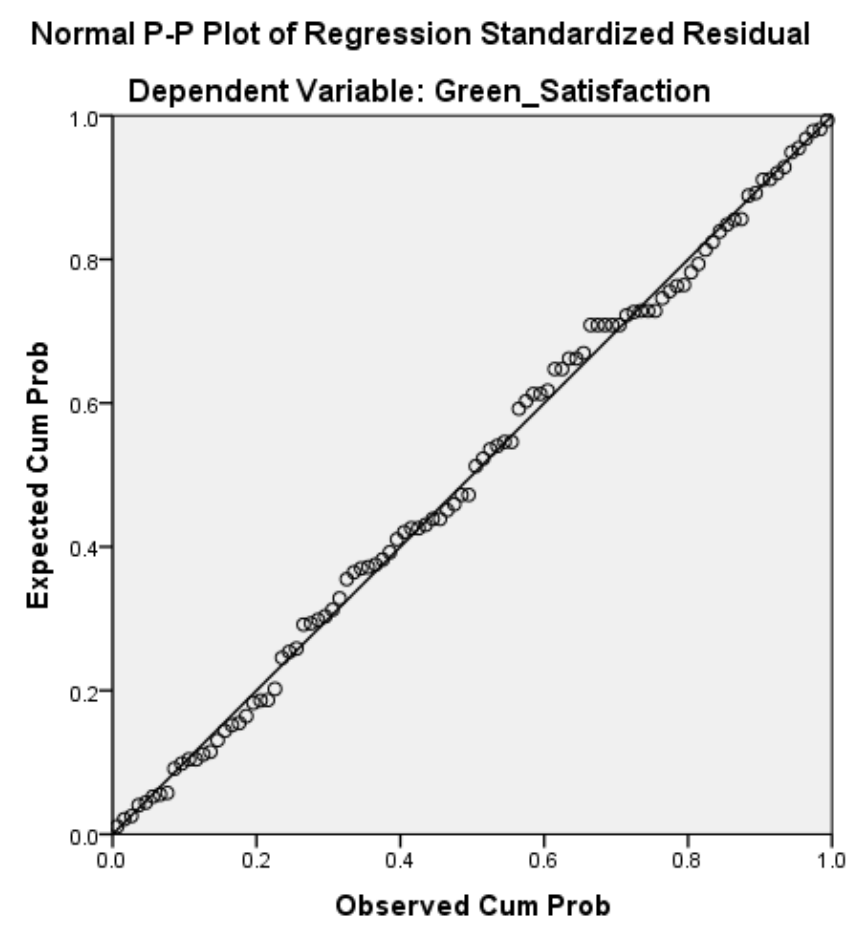

Gambar 2. Hasil uji normalitas substruktural 1

Sumber: data primer diolah, 2020

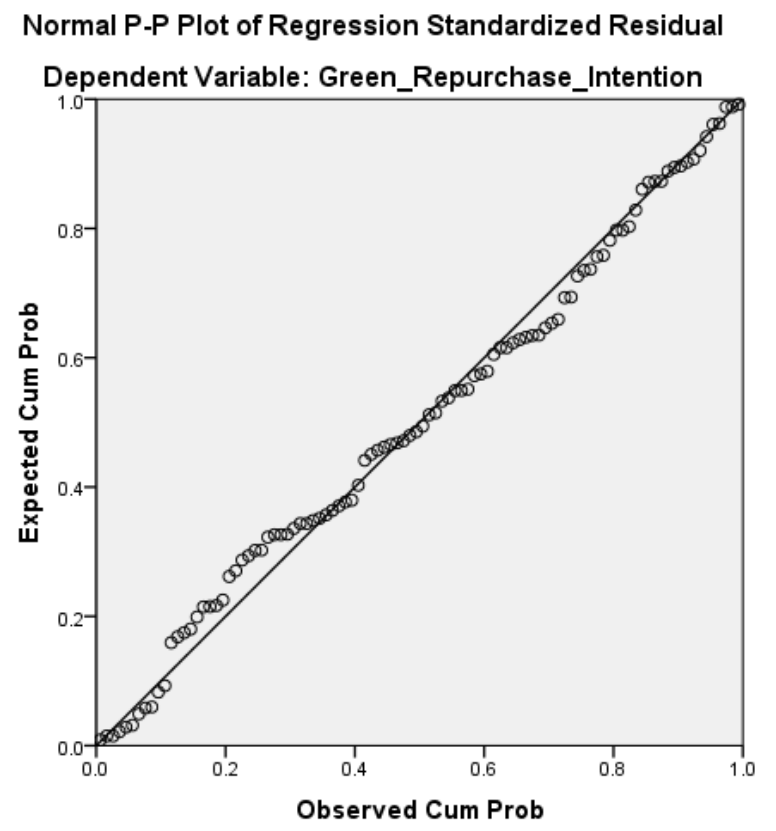

Gambar 3. Hasil uji normalitas substruktural 1

Sumber: data primer diolah, 2020 
Berdasarkan gambar tersebut(Normal P-P Plot ofRegression Standardized Residual) diketahui bahwa data menyebar disekitar garis diagonal. Maka model regresi tersebut memenuhi asumsi normalitas.

\section{Uji Multikolinearitas}

Tabel 8. Hasil Uji Multikolinearitas Substruktural 1

\begin{tabular}{lllc}
\hline \multicolumn{3}{c}{ Coefficients $^{\mathbf{a}}$} \\
\cline { 3 - 4 } Model & \multicolumn{2}{c}{ Collinearity Statistics } \\
\cline { 2 - 4 } & & Tolerance & VIF \\
\hline \multirow{2}{*}{ (Constant) } & & 1,162 \\
\cline { 2 - 4 } & Environmental Consciousness & 0,860 & 1,162 \\
\cline { 2 - 4 } & Green Perceived Value & 0,860 & \\
\hline
\end{tabular}

a. Dependent Variable: Green Satisfaction

Sumber: Data primer diolah pada tahun 2020

Tabel 9. Hasil Uji Multikolinearitas Substruktural 2

\begin{tabular}{lllc}
\hline \multicolumn{3}{c}{ Coefficients $^{\mathbf{a}}$} \\
\hline \multirow{2}{*}{ Model } & \multicolumn{2}{c}{ Collinearity Statistics } \\
\cline { 3 - 4 } & (Constant) & & VIF \\
\hline $1 \quad$ Environmental Consciousness & 1,358 \\
\hline \multicolumn{2}{l}{ Green Perceived Value } & 0,736 & 1,448 \\
\hline & Green Satisfaction & 0,691 & 1,658 \\
\hline
\end{tabular}

a. Dependent Variable: Green Repurchase Intention

Sumber: Data primer diolah pada tahun 2020

Berdasarkan Tabel di atas coeficient di atas dapat dijelaskan bahwa pada bagian collinieritas statistic menunjukan angka VIF tidak lebih besar dari 10 dan tolerance lebih dari 0,10. Berdasarkan hasil tersebut dapat diketahui bahwa model regresi substruktural I dan substruktural II ini tidak terdapat multikolonieritas, sehingga model ini dapat dipakai.

\section{Uji Heterokedastisitas}

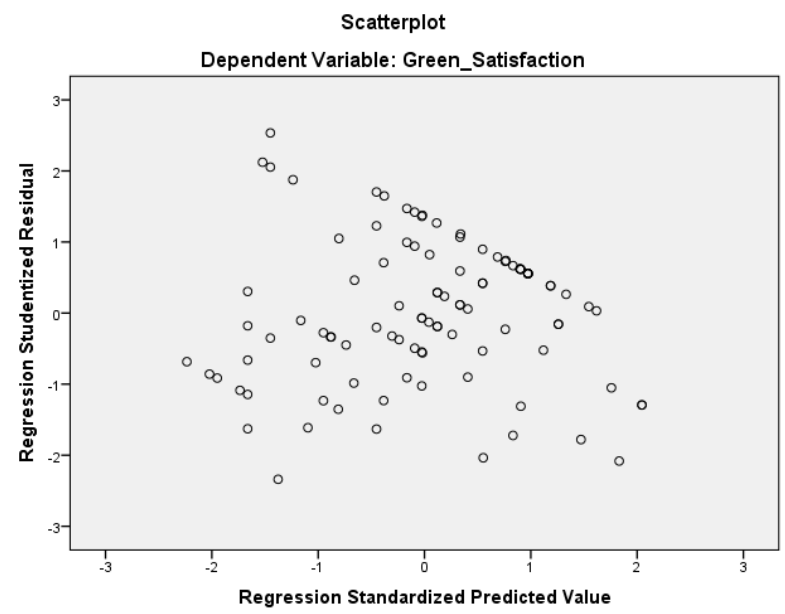

Gambar 4. Uji heterokedastisitas

Sumber: Data primer diolah pada tahun 2020 


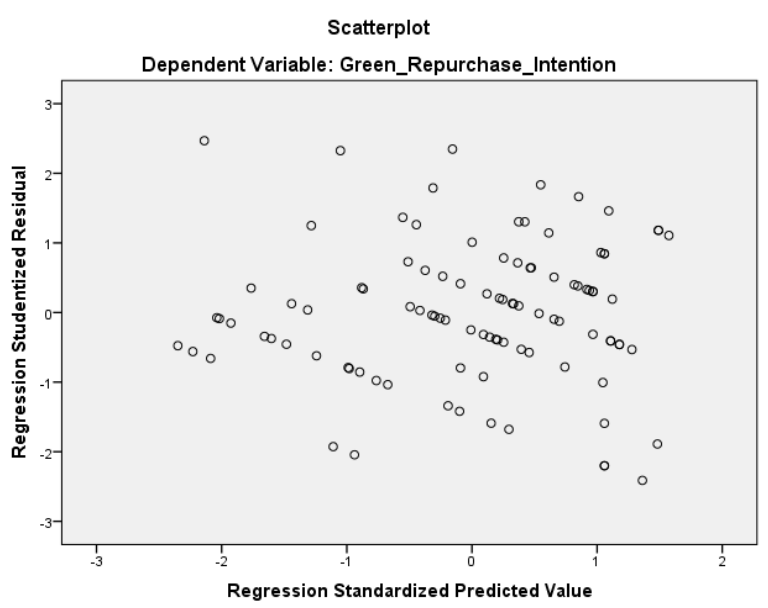

Gambar 5. Uji heterokedastisitas

Sumber: Data primer diolah pada tahun 2020

Berdasarkan gambar grafik heteroskedastisitas diatas menunjukan bahwa tidak ada pola tertentu, seperti titik-titik (poin) yang membentuk suatu pola tertentu yang teratur (bergelombang, melebar, kemudian menyempit) dan tidak ada pola yang jelas, maka dapat disimpulkan model regresi dalam penelitian ini tidak terjadi heteroskedastisitas.

\section{Uji Hipotesis}

Uji Parsial Uji t

Tabel 10. Hasil Uji Parsial (Uji t) substruktural 1

\begin{tabular}{|c|c|c|c|c|c|}
\hline \multicolumn{6}{|c|}{ Coefficients $^{a}$} \\
\hline \multirow[t]{2}{*}{ Model } & \multicolumn{2}{|c|}{$\begin{array}{c}\text { Unstandardized } \\
\text { Coefficients }\end{array}$} & \multirow{2}{*}{$\begin{array}{c}\text { Standardized } \\
\text { Coefficients }\end{array}$} & \multirow{2}{*}{$\mathrm{T}$} & \multirow{2}{*}{ Sig. } \\
\hline & B & $\begin{array}{l}\text { Std. } \\
\text { Error }\end{array}$ & & & \\
\hline \multirow{3}{*}{$\begin{array}{l}\text { (Constant) } \\
\text { Environmental } \\
\text { Consciousness } \\
\text { Green Perceived } \\
\text { Value }\end{array}$} & 3,725 & 1,698 & & 2,193 & 0,031 \\
\hline & 0,361 & 0,089 & 0,344 & 4,044 & 0,000 \\
\hline & 0,485 & 0,099 & 0,415 & 4,881 & 0,000 \\
\hline
\end{tabular}

a. Dependent Variable: Green Satisfaction

Sumber: Data primer diolah, tahun 2020

Tabel 11. Hasil Uji Parsial (Uji t) substruktural 2

\begin{tabular}{|c|c|c|c|c|c|c|}
\hline \multicolumn{7}{|c|}{ Coefficients $^{a}$} \\
\hline \multirow{3}{*}{\multicolumn{2}{|c|}{ Model }} & \multirow{2}{*}{\multicolumn{2}{|c|}{$\begin{array}{l}\text { Unstandardized } \\
\text { Coefficients }\end{array}$}} & \multirow{3}{*}{$\begin{array}{c}\text { Standardize } \\
\text { d } \\
\text { Coefficients } \\
\text { Beta }\end{array}$} & \multirow{3}{*}{$\mathrm{T}$} & \multirow{3}{*}{ Sig. } \\
\hline & & & & & & \\
\hline & & B & $\begin{array}{l}\text { Std. } \\
\text { Error }\end{array}$ & & & \\
\hline \multirow[t]{2}{*}{1} & (Constant) & 3,316 & 1,372 & & 2,416 & 0,018 \\
\hline & $\begin{array}{l}\text { Environmental } \\
\text { consciousness }\end{array}$ & 0,136 & 0,076 & 0,174 & 1,781 & 0,078 \\
\hline
\end{tabular}


Jurnal Ilmiah Mahasiswa Manajemen, Bisnis dan Akuntansi 2(4) Agustus 2020

\begin{tabular}{llllll}
\hline Green perceived value & 0,239 & 0,088 & 0,276 & 2,733 & 0,007 \\
Green satisfaction & 0,183 & 0,080 & 0,247 & 2,283 & 0,025 \\
\hline
\end{tabular}

a. Dependent Variable: Green Repurchase Intention

Sumber: Data primer diolah, tahun 2020

Berdasarkan kedua tabel di atas, maka dapat dilihat hasil uji t yang menunjukkan hasil pengaruh tiap variabel karena $t_{\text {hitung }}>t_{\text {tabel }}$ dan signifikansi $<0,05$.

\section{Koefsien determinasi $\left(R^{2}\right)$}

Tabel 12.Hasil Uji Koefisien Determinasi Substruktural 1

\begin{tabular}{lrrrr}
\hline \multicolumn{5}{c}{ Model Summary $^{\mathbf{b}}$} \\
\hline Model & $\mathrm{R}$ & R Square & $\begin{array}{c}\text { Adjusted R } \\
\text { Square }\end{array}$ & $\begin{array}{c}\text { Std. Error of the } \\
\text { Estimate }\end{array}$ \\
\hline 1 & $0,630^{a}$ & 0,397 & 0,385 & 2,112 \\
\hline
\end{tabular}

a. Predictors: (Constant), Green Perceived Value, Environmental Consciousness

b. Dependent Variable: Green Satisfaction

Sumber: Data primer diolah, Tahun 2020

Berdasarkan Tabel di atas besarnya Adjusted $R$ Square adalah 0,385 hal ini berati 38,5\% green satisfactiondapat dijelaskan oleh variabelenvironmental consciousness dan variabelgreen perceived value. Sedangkan sisanya 61,5\% (100\% - 38,5\%) dijelaskan oleh faktor lain diluar model.

Tabel 13. Hasil Uji Koefisien Determinasi Substruktural 2

\begin{tabular}{lcccc}
\hline \multicolumn{4}{c}{ Model Summary $^{\mathrm{b}}$} \\
Model & $\mathrm{R}$ & $\mathrm{R}$ Square & $\begin{array}{c}\text { Adjusted R } \\
\text { Square }\end{array}$ & $\begin{array}{c}\text { Std. Error of the } \\
\text { Estimate }\end{array}$ \\
\hline 1 & $0,567^{\mathrm{a}}$ & 0,321 & 0,300 & 1,665 \\
\hline
\end{tabular}

a. Predictors: (Constant), Green Satisfaction, Green Perceived Value, Environmental Consciousness,

b. Dependent Variable: Green Repurchase Intention

Sumber: Data primer diolah, Tahun 2020

Berdasarkan tabel diatas besarnya Adjusted $R$ Square adalah0,300 hal ini berati 30,0,\% variabel green repurchase intention dapat dijelaskan oleh variabel environmental consciousness, variabelgreen perceived value dan variabel green satisfaction. Sebesar 70,0\% (100\% - 30,0\%) dapat dijelaskan oleh variabel lain yang tidak ada dalam model penelitian ini. 


\section{Analisis Korelasi}

Tabel 14.Hasil Uji Analisis Korelasi

\begin{tabular}{|c|c|c|c|}
\hline \multicolumn{4}{|c|}{ Correlations } \\
\hline & & $\begin{array}{l}\text { Environmental } \\
\text { Consciousness }\end{array}$ & $\begin{array}{l}\text { Green } \\
\text { Perceived } \\
\text { Value }\end{array}$ \\
\hline \multirow{3}{*}{$\begin{array}{l}\text { Environmental } \\
\text { Consciousness }\end{array}$} & Pearson Correlation & 1 & 0,374 \\
\hline & Sig. (2-tailed) & & 0,000 \\
\hline & $\mathrm{N}$ & 100 & 100 \\
\hline \multirow{3}{*}{$\begin{array}{l}\text { Green Perceived } \\
\text { Value }\end{array}$} & Pearson Correlation & 0,374 & 1 \\
\hline & Sig. (2-tailed) & 0,000 & \\
\hline & $\mathrm{N}$ & 100 & 100 \\
\hline
\end{tabular}

Sumber: Data primer diolah, Tahun 2019

Berdasarkan tabel diatas dapat dijelaskan bahwa environmental consciousnessdengangreen perceived value memiliki nilai sebesar $0,374>0,25$ dan masuk ke kategori tingkatan hubungan korelasi cukup kuat.

\section{Analisis Jalur}

\section{Koefisien Jalur}

Tabel 15. Hasil Uji Koefisien Jalur Substruktural 1

\begin{tabular}{lrrrr}
\hline \multicolumn{5}{c}{ Model Summary $^{\mathbf{b}}$} \\
\hline Model & $\mathrm{R}$ & R Square & $\begin{array}{c}\text { Adjusted R } \\
\text { Square }\end{array}$ & $\begin{array}{c}\text { Std. Error of the } \\
\text { Estimate }\end{array}$ \\
\hline 1 & $0,630^{a}$ & 0,397 & 0,385 & 2,112 \\
\hline
\end{tabular}

a. Predictors: (Constant), Green Perceived Value, Environmental Consciousness

b. Dependent Variable: Green Satisfaction

\begin{tabular}{|c|c|c|c|c|c|}
\hline \multicolumn{6}{|c|}{ Coefficients $^{a}$} \\
\hline \multirow[t]{2}{*}{ Model } & \multicolumn{2}{|c|}{$\begin{array}{c}\text { Unstandardized } \\
\text { Coefficients }\end{array}$} & \multirow{2}{*}{$\begin{array}{c}\begin{array}{c}\text { Standardized } \\
\text { Coefficients }\end{array} \\
\text { Beta }\end{array}$} & \multirow{2}{*}{$\mathrm{T}$} & \multirow{2}{*}{ Sig. } \\
\hline & B & $\begin{array}{l}\text { Std. } \\
\text { Error }\end{array}$ & & & \\
\hline \multirow{3}{*}{$\begin{array}{l}\text { (Constant) } \\
\text { Environmental } \\
\text { Consciousness } \\
\text { Green Perceived } \\
\text { Value }\end{array}$} & 3,725 & 1,698 & & 2,193 & 0,031 \\
\hline & 0,361 & 0,089 & 0,344 & 4,044 & 0,000 \\
\hline & 0,485 & 0,099 & 0,415 & 4,881 & 0,000 \\
\hline
\end{tabular}

a. Dependent Variable: Green Satisfaction

Sumber: Data primer diolah, Tahun 2020

Berdasarkan tabel 15. , persamaan regresi dapat dibuat dari hasil output coefficients pada kolomstandardized coefficients beta. Berikut persamaan regresi substruktural 1:

$€_{1}=\sqrt{1-R^{2}}=\sqrt{1-0,397}=0,776$

$\mathrm{Y} 1=0,344 \mathrm{X} 1+0,415 \mathrm{X} 2+0,776$ 
Nilai-nilai $\mathrm{P}_{1}, \mathrm{P}_{2}$ dan $€_{1}$ dapat dijelaskan sebagai berikut:

a. Koefisien regresi variabel Environmental Consciousness $\left(\mathrm{P}_{1}\right)=0,344$

Koefisien regresi untuk X1 sebesar 0,344 artinya setiap penambahan 1 satuan pada variabel environmental consciousness (X1), maka akan menambah green perceived value sebesar 0,344 .

b. Koefisien regresi variabel green perceived value $\left(\mathrm{P}_{2}\right)=0,415$

Koefisien regresi untuk X2 sebesar 0,415 artinya setiap penambahan 1 satuan pada variabel green perceived value (X2), maka akan menambah green satisfaction sebesar 0,415 .

c. Nilai residu $\left(€_{1}\right)=0,776$

Nilai residu yang sebesar 0,776 menunjukkan green satisfaction yang tidak dapat dijelaskan oleh variabel environmental consciousness (X1) dan variabel green perceived value $(\mathrm{X} 2)$ diabaikan atau sama dengan nol (0).

Tabel 16.Hasil Uji Koefisien Jalur Substruktural 2 Model Summaryb

\begin{tabular}{lrrrr}
\hline Model & R & R Square & $\begin{array}{c}\text { Adjusted R } \\
\text { Square }\end{array}$ & $\begin{array}{c}\text { Std. Error of the } \\
\text { Estimate }\end{array}$ \\
\hline 1 & $0,567 \mathrm{a}$ & 0,321 & 0,300 & 1,665 \\
\hline
\end{tabular}

a. Predictors: (Constant), Green Satisfaction, Green Perceived Value, Environmental Consciousness,

b. Dependent Variable: Green Repurchase Intention

\begin{tabular}{|c|c|c|c|c|c|c|}
\hline \multicolumn{7}{|c|}{ Coefficients ${ }^{a}$} \\
\hline \multirow{2}{*}{\multicolumn{2}{|c|}{ Model }} & \multicolumn{2}{|c|}{$\begin{array}{c}\text { Unstandardized } \\
\text { Coefficients }\end{array}$} & \multirow{2}{*}{$\begin{array}{c}\begin{array}{c}\text { Standardized } \\
\text { Coefficients }\end{array} \\
\text { Beta }\end{array}$} & \multirow{2}{*}{$\mathrm{T}$} & \multirow{2}{*}{ Sig. } \\
\hline & & B & $\begin{array}{l}\text { Std. } \\
\text { Error }\end{array}$ & & & \\
\hline \multirow[t]{4}{*}{1} & (Constant) & 3,316 & 1,372 & & 2,416 & 0,018 \\
\hline & $\begin{array}{l}\text { Environmental } \\
\text { consciousness }\end{array}$ & 0,136 & 0,076 & 0,174 & 1,781 & 0,078 \\
\hline & $\begin{array}{l}\text { Green perceived } \\
\text { value }\end{array}$ & 0,239 & 0,088 & 0,276 & 2,733 & 0,007 \\
\hline & $\begin{array}{l}\text { Green } \\
\text { satisfaction }\end{array}$ & 0,183 & 0,080 & 0,247 & 2,283 & 0,025 \\
\hline
\end{tabular}

a. Dependent Variable: Green Repurchase Intention

Sumber: Data primer diolah, tahun 2020

Berdasarkan tabel IV-20, persamaan regresi dapat dibuat dari hasil output coefficients pada kolom standardized coefficients beta. Berikut persamaan regresi substruktural 2:

$€_{2}=\sqrt{1-R^{2}}=\sqrt{1-0,321}=0,824$

$\mathrm{Y} 2=0,174 \mathrm{X} 1+0,276 \mathrm{X} 2+0,247 \mathrm{Y} 1+0,824$

Nilai-nilai $P_{1}, P_{2}, P_{3}$ dan $€_{2}$ dapat dijelaskan sebagai berikut: 
a. Koefisien regresi variabel environmental consciousness $\left(\mathrm{P}_{1}\right)=0,174$

Koefisien regresi untuk X1 sebesar 0,174 artinya setiap penambahan 1 satuan pada variabel environmental consciousness (X1), maka akan menambah green repurchase intention sebesar 0,174.

b. Koefisien regresi variabel green perceived value $\left(\mathrm{P}_{2}\right)=0,276$

Koefisien regresi untuk X2 sebesar 0,276 artinya setiap penambahan 1 satuan pada variabel green perceived value (X2), maka akan menambah green repurchase intention sebesar 0,276.

c. Koefisien regresi variabelgreen satisfaction $\left(\mathrm{P}_{3}\right)=0,247$

Koefisien regresi untuk $\mathrm{Y} 1$ sebesar 0,247 artinya setiap penambahan 1 satuan pada variabel green satisfaction(Y1), maka akan menambah green repurchase intention sebesar 0,247.

d. Nilai residu $\left(€_{2}\right)=0,824$

Nilai residu yang sebesar 0,824 menunjukkan green repurchase intentionyang tidak dapat dijelaskan oleh variabel environmental consciousness $(\mathrm{X} 1)$, variabel green perceived value $(\mathrm{X} 2)$ dan variabel green satisfaction (Y1) diabaikan atau sama dengan nol (0).

\section{Diagram Jalur}

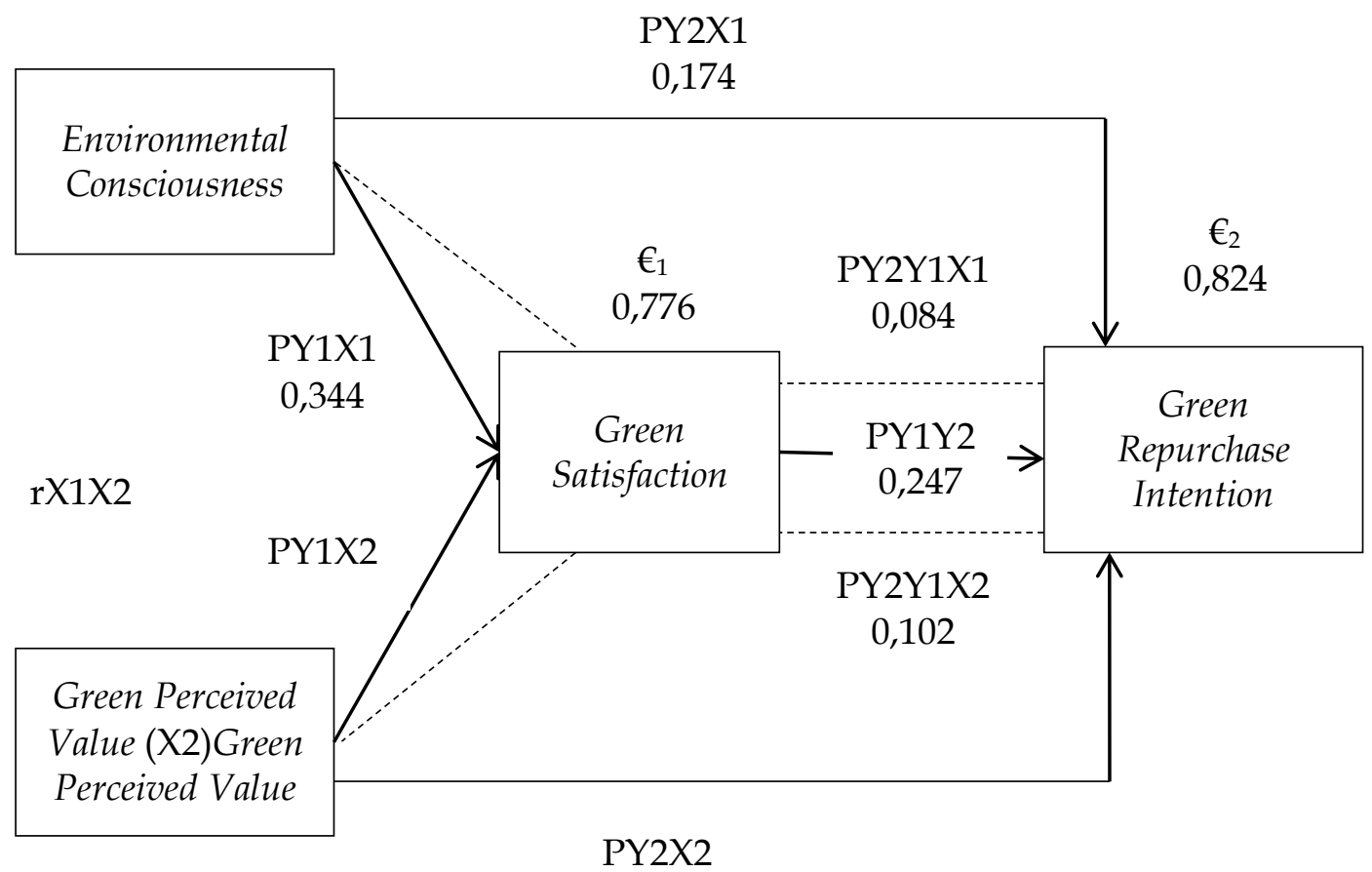

Gambar 6. Diagram Jalur 


\section{Uji Sobel}

Tabel 17. Hasil Uji Sobel Substruktural 1

\begin{tabular}{lcc}
\hline Test Statistic & Standar Eror & P-Value \\
1.99248965 & 0.03315601 & 0.04631736 \\
\hline
\end{tabular}

Sumber: Data primer diolah, 2020

Berdasarkan tabel IV-21, menunjukan test statistic $>\mathrm{t}$ tabel yaitu 1,992 >1,9844 dan p-value $<$ a yaitu $0,046<0,05$. Maka dapat disimpulkan bahwa green satisfaction dapat memediasi antara variabel environmental consciousness dengan variabel green repurchase intention.

Tabel 18. Hasil Uji Sobel Substruktural 2

\begin{tabular}{rrr}
\hline Test Statistic & Standar Eror & P-Value \\
2.07268235 & 0.04282132 & 0.03820185 \\
& & \\
\hline
\end{tabular}

Sumber: data primer diolah tahun, 2020

Berdasarkan tabel IV-22, menunjukan test statistic $>t$ tabel yaitu 2,072 $>1,9844$ dan p-value $<$ a yaitu 0,038 < 0,05. Maka dapat disimpulkan bahwa green satisfaction dapat memediasi antara variabel green perceived value dengan variabel green repurchase intention.

\section{Pembahasan}

1. Pengaruh environmental consciousness terhadap green satisfaction

Berdasarkan hasil uji statistik yang sebelumnya telah dilakukan maka dapat diketahui bahwa pengaruh environmental consciousness terhadap green satisfactionsebesar 0,344atau 34,4\%. Hal ini menunjukan bahwa Kesadaran lingkungan menjadi hal yang dapat mempengaruhi kepuasan terhadap pembelian sayuran organik.Jika pelanggan memiliki tingkat kesadaran lingkungan yang tinggi dan dikaitkan dengan klaim yang diposisikan oleh pemasar dan pembuat kebijkan, maka akan menghasilkan satisfaction yang tinggi.

2. Pengaruh green perceived value terhadap green satisfaction

Berdasarkan hasil uji statistik yang sebelumnya telah dilakukan maka dapat diketahui bahwa pengaruh green perceived valueterhadap green satisfactionsebesar 0,415atau 41,5 $\%$. Hal ini menunjukan bahwa Nilai yang dirasakan konsumen secara keseluruhan, berkaitan dengan manfaat yang diberikan pada kebutuhan organik dianggap sebagai faktor penting yang menentukan kepuasan.

3. Pengaruh environmental consciousness terhadap green repurchase intention

Berdasarkan hasil uji statistik yang sebelumnya telah dilakukan maka dapat diketahui bahwa pengaruhenvironmental consciousness terhadap green repurchase intentionsebesar 0,174 atau $17,4 \%$. Hal ini dikarenakan individu belum menyadari masalah lingkungan dan belum menunjukan dukungan usaha dalam menumbuhkan dan membina kesadaran untuk melestarikan lingkungan berdasarkan tata nilai, yaitu tata nilai dari lingkungan. Konsumen yang memiliki informasi yang cukup tentang isu-isu 
permasalahan lingkungan akan memilih produk ramah lingkungan, akan tetapi sebagian orang masih mengabaikan hal tersebut dan belum menjadi kebiasaan bagi setiap orang.Kurangnya kesadaran lingkungan pada masyarakat menyebabkan konsumen tidak melakukan pembelian ulang terhadap sayuran organik. Environmental consciousness tidak berpengaruh terhadap green repurchase intention di karenakan kurangnya kesadaran lingkungan masayarakt di kabupaten Kebumen masih rendah.

4. Pengaruh green perceived value terhadapgreen repurchase intention

Berdasarkan hasil uji statistik yang sebelumnya telah dilakukan maka dapat diketahui bahwa pengaruh green perceived valueterhadap green repurchase intention sebesar 0,276 atau $27,6 \%$. Hal ini dikarenakanapabila konsumen merasakan keuntungan dan manfaat terhadap sayuran organik maka konsumen akan melakukan pembelian. Ketika seorang konsumen melakukan evaluasi terhadap sayuran organik yang dikonsumsi, mereka cenderung untuk membeli ulang produk tersebut. Semakin tinggi green perceived valueakan menciptakan green repurchase intention.

5. Pengaruh green satisfaction terhadap green repurchase intention

Berdasarkan hasil uji statistik yang sebelumnya telah dilakukan maka dapat diketahui bahwa pengaruh green satisfactionterhadap green repurchase intention sebesar 0,274 atau $27,4 \%$. Hal ini menunjukan bahwa semakin tinggi green satisfaction dari pemenuhan konsumsi yang memuaskan dengan pertimbangan lingkungan sehingga, sesuai dengan harapan dan kebutuhan bagi konsumen.Kepuasan pelanggan sebagai faktor positif yang mempengaruhi keputusan terhadap pembelian ulang pada sayuran organic.

6. Pengaruh environmental consciousness terhadap green repurchase intentionmelaui green satisfaction.

Berdasarkan hasil uji statistik yang sebelumnya telah dilakukan maka dapat diketahui bahwa pengaruh environmental consciousness terhadap green repurchase intention melaui green satisfactionsebesar 0,084 atau $8,4 \%$. Hal ini menunjukan bahwa secara tidak langsung green perceived value melalui green satisfaction tidak mempunyai pengaruh terhadap green repurchase intention pada konsumen sayuran organik di Kabupaten Kebumen. Berdasarkan hasil uji yang digunakan dengan kalkulator sobel menunjukan bahwagreen satisfaction dapat memediasi antara variabel environmental consciousness dengan variabel green repurchase intention.

7. Pengaruh green perceived value terhadap green repurchase intention melaui green satisfaction.

Berdasarkan hasil uji statistik yang sebelumnya telah dilakukan maka dapat diketahui bahwa pengaruh green perceived value terhadap green repurchase intention melaui green satisfaction sebesar 0,102 atau $10,2 \%$. Hal ini menunjukan bahwabahwa secara tidak langsung green perceived value melalui green satisfaction tidak mempunyai pengaruh terhadap green repurchase intention pada konsumen sayuran organik di Kabupaten Kebumen. Berdasarkan hasil uji yang digunakan dengan kalkulator sobel menunjukan bahwa green satisfaction dapat memediasi antara variabel green repurchase intention dengan variabel green repurchase intention.

\section{Penutup dan Saran}


Berdasarkan hasil pembahasan analisis data melalui pembuktian terhadap hipotesis dari permasalahan yang diangkat mengenai faktor-faktor yang mempengaruhi green repurchase intention pada konsumen sayuran organik di Kabupaten Kebumen, maka dapat diperoleh kesimpulan sebagai berikut:

1. Hasil penelitian menunjukkan bahwa variabel environmental consciousness berpengaruh dan signifikan terhadap green satisfactionpada konsumen sayuran organik di Kabupaten Kebumen. Hal ini berarti,kesadaran lingkungan menjadi hal yang dapat mempengaruhi kepuasan terhadap pembelian sayuran organik.

2. Hasil penelitian menunjukkan bahwa variabel green perceived value berpengaruh dan signifikan terhadap green satisfactionpada konsumen sayuran organik di Kabupaten Kebumen. Hal ini berarti, apaila penilaian konsumen secara keseluruhan dari manfaat yang diterima dari mengkonsumsi sayuran organik maka akan menentukan kepuasan. dengan semakin tinggi penilaian konsumen terhadap manfaat yang diberikan oleh sayuran organik bagi kesehatan maka kepuasan konsumen akan meningkat.

3. Hasil penelitian menunjukkan bahwa variabel environmental consciousness tidak berpengaruh terhadap greenrepurchase intentionpada konsumen sayuran organik di Kabupaten Kebumen. Konsumen di Kabupaten Kebumen tingkat kesadaran lingkunganya masih rendah sehingga tidak menjadikan pertimbangan untuk melakukan pemembelian ulang sayuran organik.

4. Hasil penelitian menunjukkan bahwa variabel green perceived value berpengaruh dan signifikan terhadap greenrepurchase intentionpada konsumen sayuran organik di Kabupaten Kebumen. Hal ini berarti bahwa adanya nilai yang dirasakan setelah mengkonsumsi sayuran organik dan merasakan keuntungan yang diterima dan kepuasan terhadap produk sayuran organik maka konsumen akan mempunyai keinginan untuk membeli kembali.

5. Hasil penelitian menunjukkan bahwa variabel green satisfaction berpengaruh dan signifikan terhadap green repurchase intentionpada konsumen sayuran organik di Kabupaten Kebumen.Hal tersebut berarti bahwa kepuasan konsumen sebagai faktor positif yang mempengaruhi keputusan terhadap pembelian ulang produk sayuran organik.

6. Variabel environmental consciousnessberpengaruh signifikan terhadap green repurchase intentionmelalui green satisfaction. Hal tersebut menunjukkan bahwa semakin tinggi kasadaran konsumen akan lingkungan maka akan meningkatkan green satisfaction dan secara tidak langsung berpengaruh terhadap green repurchase intention.

7. Variabel green perceived value berpengaruh signifikan terhadap green repurchase intentionmelalui green satisfaction. Hal tersebut berarti bahwa semakin tinggi nilai yang dirasakan setelah mengkonsumsi sayuran organik maka akan meningkatakan kepuasan dan secara tidak langsung berpengaruh terhadap green repurchase intention.

\section{Keterbatasan}

1. Penelitian ini menjelaskan $30,0 \%$ dipengaruhi oleh variabel environmental consciousness dan green perceived valueterhadap green repurchase intention melalui green satisfaction pada konsumen sayuran organic di Kabupaten Kebumen. Peneliti lain disarankan untuk untuk mengambil variabel lain karena $(100 \%-30,0 \%)=70,0 \%$ dijelaskan oleh 
faktor lain diluar model atau dipengaruhi variabel lain, serta menjadikan penelitian ini sebagai bahan referensi untuk penelitian selanjutnya.

2. Penelitian selanjutnya disarankan untuk meneliti variabel lain pada penelitian yang serupa seperti variabel green trust dan green perceived quality agar dapat memperkaya kajian dalam penelitian serupa serta agar pembaca dapat mengetahui variabel lainnya yangdapat mempengaruhi terbentuknya green repurchase intentionpada konsumen sayuran organik di Kabupaten Kebumen.

\section{Referenasi}

Ariffin, S., Yusof, J. M., Putit, L., \& Shah, M. I. A. (2016). Factors influencing perceived quality and repurchase intention towards green products. Procedia Economics and Finance, 37(16), 391-396.

Chen, Y. S., \& Chang, C. H. (2012). Enhance green purchase intentions. Management Decision, 50(3), 505-520.

Kurniawati, N. R., \& Nina, P. (2018). Pengaruh Green Perceived Value dan Green Perceived Quality untuk Meningkatkan Green Satisfaction yang Berdampak pada Repurchase Intention. E-Jurnal STIE INABA, 17(2), 1-18.

Lam, A. Y., Lau, M. M., \& Cheung, R. (2016). Modelling the relationship among green perceived value, green trust, satisfaction, and repurchase intention of green products. Contemporary Management Research, 12(1), 47-60.

Lin, C., \& Lekhawipat, W. (2014). Factors affecting online repurchase intention. Industrial Management E Data Systems. 14(4), 597-611.

Maniatis, P. (2016). Investigating factors influencing consumer decision-making while choosing green products. Journal of Cleaner Production, 132, 215-228. 